\title{
Prioritizing Major Policy Issues Regarding the Smart Schooling System Using the AHP Method
}

\author{
Young-Chool Choi ${ }^{*}$, Ji-Hye Lee ${ }^{1}$ and Hye-Jeung Lee \\ Chungbuk National University, Korea \\ Seowon University, Korea \\ Hannam University \\ *ycchoi@cbu.ac.kr,wisdom56@hanmail.net,kl0705@hnu.kr
}

\begin{abstract}
This paper attempts to identify the determinants affecting the success of the smart schooling system in Korea which is one of the leading countries across the world in terms of education through ICT, to prioritize the indicators necessary for the success of the smart schooling system in terms of weight, using the Analytical Hierarchy Process (AHP) method, and to put forward policy implications for policymakers and practitioners involved in smart school and education policy. The AHP analysis shows that the indicator teacher's commitment has the highest weight score, followed by attitudes towards e-learning and IT, implying that the individual involved in the activities of the smart schooling system should be regarded as more important than any other indicators.
\end{abstract}

Keywords: smart schooling system, smart education, AHP

\section{Introduction}

The emergence and evolution of ICT technologies lead towards the development of useful and interactive tools. As a result, ICT-based learning is becoming increasingly important and is making the learning process easier and more effective in many contexts. Korea has become one of the most advanced countries in the world in terms of ICT technology. However, it is widely held that technology alone will not make a school 'smart'. For example, many factors such as improved teaching-learning strategies, management and administrative processes, and capable, well-trained people with enthusiasm for their work can affect whether a school can become a smart school or not. The smart school is by definition a learning institution that has been systematically reinvented in terms of teaching/learning practices and school management in order to prepare children for the Information Age. The purpose of this paper is to identify the determinants of smart schooling system success in Korea, to prioritize these in terms of weight using the Analytical Hierarchy process (AHP) method, and to put forward policy suggestions for policymakers and practitioners involved in smart school and education policy.

\section{Literature Review}

The idea of the smart school is to revolutionize the education system through a holistic approach to the development of the individual, making value-based education available to anyone, any time and anywhere (Omidinia et al., 2012; Yigit et al., 2013). The smart school vision brings together the vital components required to exploit technology in order to improve the education system and the delivery of

* Corresponding Author 
education to our children, and also to achieve the objective of improving technological awareness. A smart school will evolve over time, continuously developing its professional staff, its educational resources, and its administrative capabilities. What, then, might be the determinants affecting the success of a smart schooling system?.

Jaafar (2008) suggests four parameters which contribute to the success of smart schooling systems: curriculum, pedagogy, assessment, and teacher-learning materials. Andersson and Gronlund (2009) also discuss the challenges presented by e-learning in developing countries; they found 30 such challenges and summarized them in four categories: courses, individuals, technology, and context. Omidinia et al. (2012) present a conceptual framework for the challenges involved in e-learning (Table 1).

Table 1. Conceptual Framework of Challenges in e-Learning

\begin{tabular}{|c|c|c|}
\hline Categories & \multicolumn{2}{|c|}{ Sub-Group Challenges } \\
\hline & Student & Teachers \\
\hline Individual & $\begin{array}{l}\text {.Motivation } \\
\text {.Academic confidence } \\
\text {.Technological confidence } \\
\text {.Social support (support from } \\
\text { home and employers) } \\
\text {.Gender } \\
\text {.Age }\end{array}$ & $\begin{array}{l}\text { Technological confidence } \\
\text {.Motivation and commitment } \\
\text {.Qualification and competence } \\
\text {.Time }\end{array}$ \\
\hline \multirow[b]{2}{*}{ Courses } & Course Design & Support Provided \\
\hline & $\begin{array}{l}\text { Curriculum } \\
\text {.Subject content } \\
\text {.Teaching and learning activities }\end{array}$ & $\begin{array}{l}\text {.Support for students from } \\
\text { faculty } \\
\text {.Support for faculty }\end{array}$ \\
\hline \multirow[b]{2}{*}{ Contextual } & Organizational & Social/Cultural \\
\hline & $\begin{array}{l}\text { Knowledge } \\
\text {.Economy and funding } \\
\text {.Training of teachers and staff }\end{array}$ & $\begin{array}{l}\text { Role of teachers and student } \\
\text {.Attitudes towards e-learning and } \\
\text { IT } \\
\text {.Rules and regulations }\end{array}$ \\
\hline Technological & $\begin{array}{l}\text {.Access } \\
\text {.Cost } \\
\text {.Software and interface design } \\
\text {.Localization }\end{array}$ & \\
\hline
\end{tabular}

Source: Omidinia et al. (2012: 32).

Omidinia et al.'s conceptual framework for e-learning provides us with important parameters which contribute to smart schooling success, in the sense that the framework is comprehensive and multi-dimensional in nature and can also be applied to explaining the level of establishment of the smart schooling system in both developed and developing countries. In this study, we utilize their framework, after slightly adapting it (Figure 1). 


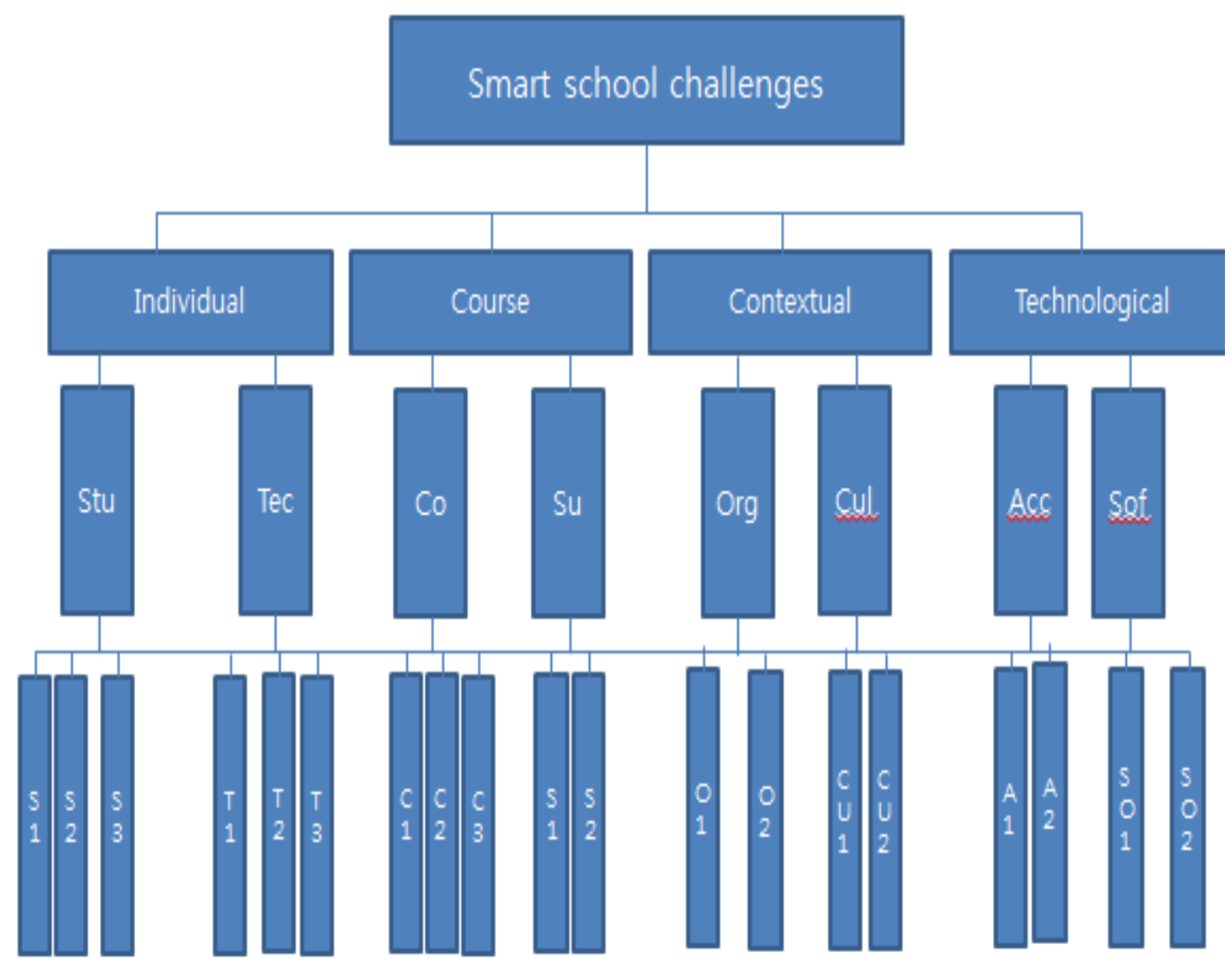

Note. Stu: student, Tec: teacher, Co: course, Su: support provided, Org: organizational, Cul: cultural, Acc: accessibility, Sof: software, S1: motivation, S2: academic confidence, S3: technical confidence, T1: commitment, T2: qualification, T3: time, C1: curriculum, C2: subject content, C3: learning activities, S1: support for students from faculty, S2: support for faculty, 01: knowledge management, O2: training for teachers and staff, CU1: attitudes towards e-learning and IT, CU2: rules and regulations, A1: access, A2: cost, SO1: interface design, SO2: digital textbooks.

\section{Figure 1. The AHP Hierarchy Model}

\section{Research Design}

\subsection{Research Question}

Basing itself on the criteria discussed above, this study attempts to provide an answer to the following question: which determinant of smart schooling system success (the individual, courses, context, technology) is more important in making the system more successful than any other? - in other words, which determinant should be regarded as more and which less important in making the smart schooling system successful?

\subsection{Survey Target and Analysis Method}

We applied AHP theory and methods to the survey data to establish the weights of various dimensions of the successful smart school and their components. The survey questions were sent to ten people: seven academic scholars and three teachers. Since this study concerns the weights of successful determinants, it adopts the Analytical Hierarchy Process (AHP) as its method of measurement. AHP is a MCDM (Multiple Criteria Decision Making) tool that has been used in almost all applications relating to decision 
making (Vaidya and Kumar, 2006). Developed by Satty (1977), it is a powerful, flexible and widely used method for solving complex problems, which operates by considering the numeric scale for the measurement of quantitative and qualitative performances. The method allows individuals to choose a value between 1 and 9 with which to rate the strength of the relationship between items in order to establish the pairwise comparison matrix so as to calculate the related eigenvalues and the eigenvectors (Chiu et al., 2010: 898). This is an Eigen-value approach to the pairwise comparisons. It is one of the very few MCDM approaches capable of handling many criteria. The most important characteristics of AHP are combining knowledge, experience, individual opinions and foresight in a logical way (Machova, 2015: 89). Therefore, unlike other statistical methods, the AHP method does not require many samples for analysis. The first step in the AHP method is to decompose the complex decision problem into the hierarchy structure, with the goal at the top of the structure. The hierarchy then descends from the more general criteria, in the second level, to sub-criteria. The hierarchical model used in this analysis is depicted in Figure 1. This model is primarily based on Omidinia et al.'s conceptual framework for e-learning success as mentioned above, and it is slightly modified in order the better to explain specifically Korean circumstances.

\section{Analysis of the Weights of Determinants Affecting Smart Schooling System Success}

\subsection{Examining Consistency}

When AHP parameters need to be compared it is essential to produce consistency, and thus it must be confirmed whether the pairwise comparison matrix is consistent. The method of examination involves using a consistency index (CI) and consistency ratio $(\mathrm{CR})$, and the equation method is as follows:

$$
\mathrm{CI}=\left(\lambda_{\max }-\mathrm{m}\right) /(\mathrm{m}-1)
$$

\section{$\mathrm{CR}=\mathrm{CI} / \mathrm{RI}$}

In this equation, $m$ represents the index number of that definite hierarchy, and RI is a random index which is obtained by the different CI values produced by the index number in different hierarchies. Satty (1977) referred to research from Oak Ridge National Laboratory and the University of Pennsylvania, Wharton School, and produced a set of RI values, presented in Table 2 .

Table 2. Random Index Chart

\begin{tabular}{|c|c|c|c|c|c|c|c|c|c|c|c|c|c|c|c|}
\hline $\mathrm{m}$ & 1 & 2 & 3 & 4 & 5 & 6 & 7 & 8 & 9 & 10 & 11 & 12 & 13 & 14 & 15 \\
\hline $\mathrm{RI}$ & 0.00 & 0.00 & 0.58 & 0.90 & 1.12 & 1.24 & 1.32 & 1.41 & 1.45 & 1.49 & 1.51 & 1.48 & 1.56 & 1.57 & 1.59 \\
\hline
\end{tabular}
Source: Chiu et al. (2010: 901 ).

Satty (1980) suggested that CI $=0$ represents the survey takers' consistency before and after the assessment of the decision factor, signifying that there are no discrepancies between the two, while $\mathrm{CI}=0.1$ is the permissible error tolerance. When $\mathrm{CI}=0.1$ the consistency of the matrix is satisfactory, and thus it can be said that the whole evaluation process reaches consistency (Chiu et al., 2010). In this study, the CR of the whole matrix is 0.07 , and thus is acceptable and satisfactory.

\subsection{Analysis of Four Dimensions Affecting Successful Smart Schooling System}

The analysis showed that the individual dimension is the most important, and that the weight value was arranged from high to low in the order 0.513 for individual, 0.295 for 
contextual, 0.104 for course, and 0.088 for technological. In addition, CI and CR were both valued below 0.1 at 0.06 and 0.07 respectively, signifying consistency in the pairwise comparison matrix index and ratio, as confirmed by the survey responses of professionals. Details regarding the order and weight of the four dimensions are sown in Table 3. Figure 2 shows global and local weights according to the different levels. Looking at the first level, we find that individual scored 0.513 at $\mathrm{L}$ and $\mathrm{G}$, as against 0.104 (course), 0.295 (contextual) and 0.088 (technological), which indicates that the category individual is more important than any other in terms of its weight of importance in affecting the success of the smart schooling system.

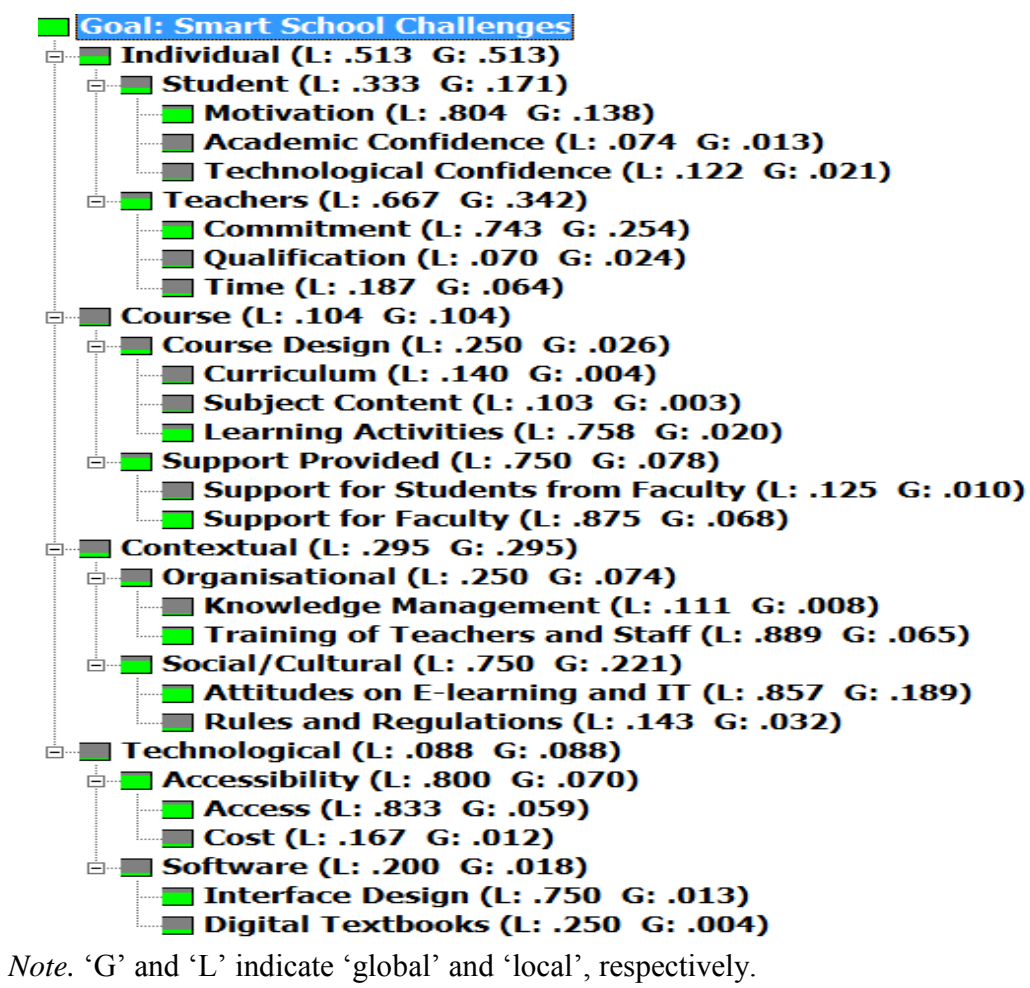

Figure 2. Global and Local Weight

Table 3. Order and Weight of the Four Dimensions

\begin{tabular}{|c|c|c|}
\hline Weight of Dimension & Weight Value & Order \\
\hline Individual & 0.513 & 1 \\
\hline Course & 0.104 & 3 \\
\hline Contextual & 0.295 & 2 \\
\hline Technological & 0.088 & 4 \\
\hline CI & 0.06 & \\
\hline CR & 0.07 & \\
\hline
\end{tabular}

\subsection{Weight Analysis of Smart Schooling System Criteria}

4.3.1. Analysis of Individual Dimension: Following the AHP procedure, the weight of the criteria of the four dimensions of a successful smart schooling system was calculated, and examined with CI and CR. Table 4 shows the order of priority in the individual dimension as: student (0.333); teachers (0.667); CI and CR, valued at 0.050 and 0.060 (both $\leq 0.1$ ). The order and weight of the individual criteria are shown in Table 4 . 
Table 4. Order and Weight Value of the Individual Dimension

\begin{tabular}{|c|c|c|}
\hline Criteria of Individual Dimension & Weight & Order \\
\hline Student & 0.333 & 2 \\
\hline Teachers & 0.667 & 1 \\
\hline CI & 0.050 & \\
\hline CR & 0.060 & \\
\hline
\end{tabular}

As Table 4 shows, in terms of the individual dimension the weight value of the teachers criterion is higher than that of the student criterion, indicating that teachers can play a more important role than students in a smart schooling system. As Figures 1 and 2 show, the student criterion has three sub-criteria: motivation, academic confidence, and technological confidence; the teachers criterion has three sub sub-criteria as well: commitment, qualifications, and time. Figure 2 shows the order of priority of the student sub-criteria as: motivation (0.804), technological confidence (0.12), and academic confidence (0.074). It also shows the order of priority of the teachers sub-criteria as: commitment (0.743), time (0.187), and qualifications (0.070).

4.3.2. Analysis of Course Dimension: Table 5 shows the order of priority of the course dimension as: support provided (0.750) and course design (0.250); and CI and CR, valued at 0.038 and 0.028 (both $\leq 0.1$ ). The order and weight of the course dimension sub-criteria are shown in Table 5.

Table 5. Order and Weight Value of the Course Dimension

\begin{tabular}{|c|c|c|}
\hline Criteria of Course Dimension & Weight & Order \\
\hline Course design & 0.250 & 2 \\
\cline { 2 - 3 } Support provided & 0.750 & 1 \\
CI & 0.038 & \\
\hline CR & 0.028 & \\
\hline
\end{tabular}

Here, the course design criteria has three sub-criteria: curriculum, subject content, and learning activities. Also, the support provided criteria has two sub-criteria: support for student from faculty, and support for faculty. Figure 2 shows the order of priority of the course design criteria as: learning activities (0.758), curriculum (0.140), and subject content (0.103). It also shows the order of priority of the support provided criteria as: support for faculty (0.875), and support for student from faculty (0.125).

4.3.3. Analysis of Contextual Dimension: Table 6 shows the order of priority of the contextual dimension as: social/cultural $(0.750)$ and organizational $(0.250)$; and CI and $\mathrm{CR}$, valued at 0.062 and 0.066 (both $\leq 0.1$ ). The order and weight of the contextual dimension sub-criteria are shown in Table 6.

\section{Table 6. Order and Weight Value of the Contextual Dimension}

\begin{tabular}{|c|c|c|}
\hline Criteria of Contextual Dimension & Weight & Order \\
\hline Organizational & 0.250 & 2 \\
\hline Social/cultural & 0.750 & 1 \\
\hline CI & 0.062 & \\
\hline CR & 0.066 & \\
\hline
\end{tabular}


As Figure 2 shows, the organizational criterion has two sub-criteria: knowledge management, and training of teachers and staff. The social/cultural criterion also has two sub-criteria: attitudes towards e-learning and IT, and rules and regulations. Figure 2 shows the order of priority of the organizational criteria as: training of teachers and staff (0.889), and knowledge management (0.111). It also shows the order of priority of the social/cultural criterion as: attitudes towards e-learning and IT (0.857), and rules and regulations $(0.143)$.

4.3.4. Analysis of Technological Dimension: Table 7 shows the order of priority of the technological dimension as: accessibility (0.800) and software (0.200); and CI and CR, valued at 0.047 and 0.052 (both $\leq 0.1$ ). The order and weight of the technological dimension are given in Table 7.

Table 7. Order and Weight Value of the Technological Dimension

\begin{tabular}{|c|c|c|}
\hline Criteria of Technological Dimension & Weight & Order \\
\cline { 2 - 3 } $\begin{array}{c}\text { Accessibility } \\
\text { Software }\end{array}$ & 0.800 & 1 \\
\cline { 2 - 3 } & 0.200 & 2 \\
\hline CI & 0.047 & \\
\hline CR & 0.052 & \\
\hline
\end{tabular}

As Figure 2 shows, the accessibility criterion has two sub-criteria: access, and cost. The software criterion also has two sub-criteria: interface design, and digital textbooks. Figure 2 shows the order of priority of the accessibility sub-criteria as: access (0.833) and cost (0.167). It also shows the order of priority of the software sub-criteria as: interface design (0.750), and digital textbooks (0.250).

4.3.5. Analysis of Overall Weights of Determinants Affecting the Smart Schooling System: Figure 3 shows the overall weights of the determinants which affect successful smart schooling in Korea. As Figure 3 shows, teachers' commitment scores the highest points (0.254), followed by attitudes towards e-learning and IT (0.189) and student's motivation (0.138). Next come support for faculty (0.068) and training of teachers and $\operatorname{staff}(0.065)$. 
Synthesis with respect to:

Goal: Smart School Challenges

Overal |lmconsistency = 080

Commitment
Attitudes on E-learning and IT
Motivation
Support for Faculty
Training of Teachers and Staff
Time

Access

Rules and Regulations

Qualification

Technological Confidence

Learning Activities

Academic Conilidence

Interface Design

Cost

Support for Students from

Knowledge Management

Curriculum

254
109

.130
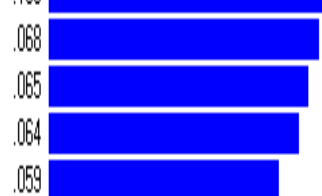

Digital Textbooks

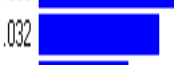

.024

.021

020

Subject Content

\begin{tabular}{l}
.013 \\
.013 \\
.013 \\
.012 \\
\hline .010 \\
.008 \\
.008 \\
.004 \\
.004 \\
.003
\end{tabular}

\section{Figure 3. Weights of Determinants Affecting a Successful Smart Schooling System}

\section{Discussion}

Smart schooling system is a newly established concept, and supports the ICT framework for improvement in learning. The purpose of this paper has been to identify the determinants affecting the success of the smart schooling system in Korea, and to prioritize these in terms of weight importance, using the AHP method. The results of this research show that the order of priority for a successful smart schooling system in Korea was as follows: individual $(0.513)>$ contextual $(0.295)>$ course $(0.103)>$ technological (0.088). This result indicates that, among other things, the individual dimension is the most important in making the smart schooling system successful. In other words, students and teachers belonging to the individual dimension play a major role in establishing a smart schooling system. The data clearly show that the individual dimension is far more important than the contextual, course, or technological dimensions as regards a successful smart schooling system. The result also shows that in the individual dimension, teacher is more important than student in making the smart schooling system successful. This is because it is generally accepted that teachers are key actors in smart schools in terms of delivering knowledge to students. These research results accord with the results of other research showing that the teacher's role in education is critical. Lee and Kwon (2014) state that teachers have adapted to the changes in the educational environment, and also that teachers need to adapt to the smart schooling system.

The course dimension shows that support provided weighs much more than course design, indicating that support for student and support for faculty matter in the smart schooling system. The results of this research clearly show that educational authorities and schools must provide suitable support for students and faculty as well in order to 
establish a smart schooling system. The contextual dimension shows that the social/cultural criterion is more important than the organizational one. It indicates that attitudes towards e-learning and IT, and rules and regulations regarding the smart schooling system, can play a major role in implementing smart schooling policy. The technological dimension is not considered very important in the smart schooling system. However, this does not mean that we can ignore interface technology and other software-related components.

To sum up, the results show that the determinant teachers commitment has the highest weight score, followed by attitudes towards e-learning and IT and student's motivation. This suggests that the Government should take determinants with a high weight score into serious consideration in implementing smart schooling policies. In other words, the research results indicate that it is important for teachers in smart schools to devote themselves to helping students to acquire computer related skills and to delivering knowledge to students. This also means that in order for the teachers to do so, they should be keen in learning web designing, graphic, network application, databases and operating system including their expertise in hardware.

The application and research methods used in this study could be used as a reference in future work. Despite the importance of the individual dimension, it should be emphasized that we cannot ignore the course, contextual and technological dimensions, and should continue to adapt the system to meet the changing environment, the new curriculum, and new technological developments. In this study, we have taken the first step in constructing a model for a successful smart schooling system. Future researchers could take this a step further by applying and modifying our methods to the various types of educational environment, for the purpose of studying differences in the determinants affecting the smart schooling system.

\section{References}

[1] A. Andersson and A. Gronlund, "A conceptual framework for e-learning in developing countries: a critical review of research challenges", Electronic Journal on Information Systems in Developing Countries, EJISDC, vol. 38, (2009), pp. 57-98.

[2] W. Y. Chiu, Y. D Lee and T. Y Lin, "Performance evaluation criteria for personal trainers: an analytical hierarchy process approach", Social Behavior and Personality, vol.38, no.7, (2010), pp 895-906.

[3] A. Jaafar, "Malaysian smart school courseware usability study: the effectiveness of analytical evaluating technique compared to empirical study"., Computers and Education, vol. 52, (2008), pp. 730-740.

[4] H. Koshan, "Multimedia school., steps toward smart school”. Tehran: Tarbiat Moalem, (2007).

[5] S. Lee and M. Kwon, "Learning effects of smart education", Journalism Science Review, vol. 14, no. 2, (2014), pp. 258-94.

[6] R. Machova, "An analytical hierarchy process model for the evaluation of the e-government development", Scientific Papers of The University of Pardubice. Series D, Faculty of Economics \& Administration, vol. 22, no. 34, (2015), pp. 88-100.

[7] S. Omidinia, M. Masrom and H. Selamat, "Determinants of smart school system success: a case study of Malaysia", International Journal of Academic Research, vol. 4, no. 1, (2012), pp. 29-36.

[8] T. L Satty, "A scaling method for priorities in hierarchical structures", Journal of Mathematical Psychology, vol. 15, no. 2, (1977), pp. 234-81.

[9] T. L. Satty, "The Analytic Hierarchy Process”, New York: McGraw Hill, (1980).

[10] O. S. Vaidya and S. Kumar, "Analytic hierarchy process: an overview of application”, European Journal of Operational Research, vo. 169, no. 1, (2006), pp. 1-29.

[11] T. Yigit, A. H. Isik and M. Ince, "Web-based learning object selection software using analytical hierarchy process". IET Softwt, vol. 8, no. 4, (2014), pp. 174-183. 
International Journal of $u-$ and e- Service, Science and Technology Vol.9, No. 5 (2016) 